\title{
ALGUNOS APUNTES SOBRE ECONOMIA MONÁSTICA FEMENINA. LAS PETICIONES DE MERCED (1598-1621)
}

\author{
POR \\ Eugenia M. Pinedo Gómez \\ Universidad de Valladolid
}

\begin{abstract}
RESUMEN
A través de este artículo se pretende añadir algunos rasgos a los estudios parciales, que sobre las órdenes femeninas vienen desarrollándose recientemente. A pesar del gran número de estudios sobre este tema, no existen trabajos de carácter general que resuman lo que fue la vida regular femenina en la Edad Moderna. Este hecho se puede explicar por la disparidad en los modos de vida y por los escasos datos que aparecen en las fuentes, lo que ha dado lugar a la aparición de estudios independientes para cada convento.
\end{abstract}

\section{ABSTRACT}

Through this article is intended to add some news to the partial studies, that on the feminine orders are researching recently. In spite of the great number of studies on this topic, do not exist projects of general character that would summarize what was the feminine regular life in the Modern Age. This fact can be explained by the disparity in the ways of life and by the scarce data that appears in the sources, that is the reason because the apparition of independent studies for each convent.

La presente comunicación, pretende añadir algunos rasgos a los estudios parciales, que sobre las órdenes femeninas vienen desarrollándose recientemen-

' Este trabajo se ha realizado gracias a los programas de apoyo a la investigación de la Fundación Caja Madrid.

Actas del I Congreso de Historia de la Iglesia y el Mundo Hispánico

Hispania Sacra, 52 (2000) 
te. Efectivamente, no existen trabajos de ámbito general que resuman lo que fue la vida del clero regular femenino en la Edad Moderna. Tal vez se deba, a que, como señala Domínguez Ortiz ${ }^{2}$, la enorme diferencia que existe entre unos centros religiosos y otros, en cuanto a bienes y medios de subsistencia, hace más difícil la síntesis, por lo que los trabajos, de reciente aparición, se centran en los estudios independientes de diferentes congregaciones. Aquí vamos a tratar de dar una idea aproximada de la situación de escasez económica que debieron sufrir las órdenes femeninas a principios del siglo XVII, basándonos en la documentación que aportan los memoriales dirigidos a la Cámara de Castilla durante el reinado de Felipe III.

Las peticiones de merced, con las que nos encontramos, son pequeños relatos de la situación en la que se hallaban algunos de los conventos. Estas peticiones, de manera individual, no son muy explícitas en cuanto a la descripción de sus medios económicos. Sin embargo, el gran número de súplicas recogidas para este período hace sospechar que no se trata simplemente de una actitud pedigüefia, sino del reflejo de una realidad que viene a sumarse a la crisis general que está desarrollándose en todos los niveles sociales del momento. Es fácil suponer que las órdenes femeninas, privadas de los medios económicos y de las salidas socioprofesionales de que disfrutaban las masculinas, se vieran arrastradas, en mayor medida, por la crisis económica.

Desde el siglo XII y hasta 1640 asistimos al florecimiento de las fundaciones femeninas, sobre todo en tierras castellanas, pasando por una etapa de mayor auge, durante los últimos años del siglo XVI y los primeros del XVII, al amparo de la reforma de Trento ${ }^{3}$. Este fenómeno contaba con la aprobación de la devoción popular, sobre todo en el caso de los monasterios más pobres, pues eran consideradas como las auténticas siervas de Dios al dedicar su vida a la penitencia, recogimiento y pobreza ${ }^{4}$. No debieron pensar lo mismo los monarcas ni el papado, sobre todo Felipe II, bajo cuyo reinado se intentó acometer una amplia reforma en base a la aceptación de la clausura estricta. Dicha reforma también alcanzaba al ámbito económico. El excesivo número de religiosas que albergaba cada monasterio hacía insuficiente su dotación, por lo que la reforma pasaba por la disminución del número de residentes hasta adecuarlo a su capacidad económica ${ }^{5}$. Sin embargo, y a pesar de este auge, las ordenes

\footnotetext{
2 A. Domínguez OrTiz, Las clases privilegiadas en el Antiguo Régimen, Madrid, 1985 (or. 1973).

3 V. LEÓN SANZ, "EI Convento de Santa Clara de Villanueva de los Infantes: apunte sociológico.» En, Archivo Ibero-americano. Julio-diciembre, 1994, Núms. 215-216, pp. 599-612.

4 J. GARCjA ORO, "La vida monástica femenina en la Espania de Santa Teresa.» Actas del Congreso Internacional Teresiano. Salamanca, 4, 7 de octubre, 1982.

${ }^{5}$ Asi se establece en el breve De statu Ecclesiarum de 7 de octubre de 1568. AGS PR, 23-98.
} 
femeninas siempre fueron mucho menores que las masculinas, debido tal vez, a la dote que éstas debían aportar ${ }^{6}$.

En cuanto al origen de las fundaciones, este era diverso, algunas de la mano real y otras por particulares. En este origen fundacional se encuentra una de las diferencias económicas que se observa entre los distintos conventos. Las de origen particular, en muchos casos, habían presentado cifras hinchadas de la dotación de su patrono, con el objeto de obtener el permiso para su establecimiento, lo que las dejaba, prácticamente, con lo procedente de las dotes de las profesas para su subsistencia ${ }^{7}$.

Por lo que se desprende del análisis de los diferentes estudios parciales, los medios económicos con los que contaban las órdenes femeninas se reducían a juros, arrendamientos, censos, dotes y limosnas. Hasta finales del siglo XVI estos ingresos resultaban suficientes, en gran medida, para cubrir sus necesidades. Sin embargo, la crisis económica que se desarrolla desde estas fechas y que cubre todo el siglo XVII, afectaría, sin lugar a dudas, a estas fuentes de ingresos.

La devaluación de la moneda, con las nuevas emisiones de vellón, afectó fuertemente a la deuda pública. El numerario procedente de esta deuda formaba la mayor parte de sus ingresos, un $35,5 \%$ del tota $1^{8}$, procedentes de donaciones reales y con carácter de juros de heredad. Al comenzar la crisis hacendística una de las medidas para sanear y equilibrar las rentas era evitar el pago de los intereses de los juros que habían superado los recursos de la Corona ${ }^{9}$. Además hay que tener en cuenta que los títulos en manos de eclesiásticos raras veces superaban los $50.000 \mathrm{mrs}$. situados, por lo general, sobre alcabalas, cuyas rentas eran bajas. Además, estas concesiones en su mayoría eran antiguas y con el paso del tiempo la tendencia de los monarcas a otorgarlas fue disminuyendo, por lo que eran muy pocos los conventos con situados en rentas con mayores beneficios, es decir, las de nueva creación ${ }^{10}$.

Otra de las fuentes de ingresos más importantes eran, sin duda, los censos. Una forma segura de inversión para quienes disponían de numerario y no tenían

6 B. BArReIro MALlón, «El monacato femenino en la Edad Modema. Demografía y estructura socialn, Actas del I Congreso Internacional del monacato femenino en España, Portugal y América. 1492-1992, Universidad de León, 1992, pp. 57-74.

${ }^{7}$ lbid., p. 58.

${ }^{8}$ M. C. SoRiano Truguero, "Los modos de subsistencia clarianos: las fuentes de ingresos del convento de Santa Clara de Madrid (siglos XVII-XVIII). Archivo Ibero-americano, enero-junio, 1994, Núms. 213-214, pp. 545-566.

${ }^{9}$ P. Toboso SÁNCHEZ, La deuda pública castellana durante el Antiguo Régimen. Juros y su liquidación en el siglo XIX, Instituto de Estudios Fiscales, Ministerio de Economia y Hacienda, Madrid, 1987.

${ }^{10}$ Ibid., pp. 210-211. 
otros medios para colocarlo. Sin embargo, esta forma de inversión comenzaría a no ser tan rentable desde finales del siglo XVI. Durante los primeros años del XVI la rentabilidad de los censos alcanzaba el $7,14 \%$ mientras que a principios del XVII había descendido al 5\% y continuaría a la baja llegando al 3,3\% al comenzar el siglo XVIII. En 1611 la abadesa del monasterio de Santa María la Real de las Huelgas de Burgos, describía a través de un memorial en septiembre de 1618, la precaria situación que sufría el inmueble y la imposibilidad de repararlo de sus propios recursos «porque la hacienda del dicho convento está muy menoscavada por averse subido los censos y variado los arrendamientos y no poder sustentar las relijiosas y 24 capellanes, otros oficiales y criados que inescusablemente sustenta ${ }^{11}$. Hay que entender la expresión (subida de los censos» como una rebaja del tipo de interés que percibía este convento. Según el lenguaje de la época se decía que un censo se situaba a 14.000 al millar lo que significaba que por cada mil maravedís de renta se debían invertir 14.000 de capital; asi pues, «subin" o «crecer», por ejemplo a 20.000 o a 30.000 , suponía que para percibir mil maravedís había que haber invertido 20.000 o 30.000 . Además a este descenso hay que añadir la tendencia de los censatarios a no hacer frente a los pagos de los réditos. Junto a las numerosas peticiones para rebajar el tipo de interés a pagar que llegaban a la Cámara de Castilla, nos encontramos con un número parecido de peticiones para eludir el pago o retrasarlo. A tal punto llegó esta práctica que a mediados del reinado de Felipe III algunas de las posesiones de estos censatarios fueron puestas en manos de administradores que trataron de encauzar estas deudas. Aún así algunos conventos no conseguían cobrar sus rentas. El convento de Santa Clara de la ciudad de Zamora tenía una renta de $85.000 \mathrm{mrs}$. desde 1538 , sobre los lugares de Riaño, Salio y La Puerta, en la provincia de León, pertenecientes al conde de Alba de Liste, y a la altura de 1613 pedían una certificación al Archivo de Simancas para demostrar esta deuda y poder cobrarla ${ }^{12}$. Presumiblemente se trataría de una renta en los censos que el conde tenía cargados sobre estos lugares. Para mayor dificultad, en 1613, el conde de Alba de Liste puso a la venta estas villas para hacer frente al pago de otros réditos. La deuda con el convento de Santa Clara ascendía a $6.375 .000 \mathrm{mrs}$., la cual ignoramos si fue satisfecha pues su rastro se pierde en este año.

Por otro lado, las dotes, habían funcionado como elemento sustentador, en ocasiones prácticamente el único, de muchos cenobios femeninos. Algunos estudios hablan del enriquecimiento de los conventos en base a las dotes de las hijas de grandes familias nobles. Pero olvidan señalar que desde finales del

11 AGS, CC., Memoriales leg. 1113, exp. 68.

12 AGS, CC., Memoriales, leg. 1022. 
$\mathrm{XVI}$, y en algunos casos antes, la nobleza atraviesa un periodo de escasez de numerario. Son grandes casas y linajes, poseen palacios y villas, pero carecen de efectivo. La mayoría tiene sus posesiones cargadas de censos cuyos réditos no pueden pagar. Y no es una práctica inusual imponer un censo para casar a una hija o para meterla monja. Tampoco lo es la práctica contraria, es decir, velar a una hija para que la otra pueda llevar una dote al matrimonio digna de su status.

En 1620, Don Bernardo Castillo de Vargas, Doña Mariana de Vitoria, su mujer, y Doña Catalina de Vitoria, su hija mayor, enviaban un memorial a la Cámara de Castilla suplicando «se apruebe y confirme una escriptura, que en favor de doña Beatriz y dofia Leonor, han otorgado con información de utilidad y licencia de justicia en esta manera: que porque la dicha Catalina, después de los días de su madre, sucede en un vínculo de 850 ducados de renta, y demás de esto, tiene derecho a otro del mismo valor, faltando la dicha dona Beatriz, que oy le posee, y doña Leonor su hermana, que ambas tienen hávito de monjas en el monasterio de la Concepción Francisca y le es de mucho veneficio que ambas profesen porque se viene a juntar en la dicha doña Catalina ambos mayorazgos, por escluir los fundadores del mayorazgo de la dicha dofia Beatriz, religiosas $^{13}, y$

Todo esto hace suponer que las dotes que aportan las novicias a su entrada en el convento no fueran, al menos en este periodo, tan fastuosas como algunos autores señalan. En estos casos las dotes de las profesas se reducen a una parte del usufructo del vínculo heredado por la hermana mayor, que como ya hemos señalado, en numerosas ocasiones se encuentra sujeto a la paga de réditos ${ }^{14}$. Debido a esto, en muchos conventos, la imposición de las pruebas de nobleza, para ingresar en la communidad, en realidad suponen demostraciones de calidad económica.

Por lo que se refiere a los arrendamientos, la estructura de este tipo de ingreso depende de cada convento y su situación. Pero en general el cobro era mayoritariamente en especie, para aquellos situados en zonas rurales, con alguna parte en dinero; mientras que los conventos urbanos reducían sus arrendamientos a las fincas urbanas y los alquileres ${ }^{15}$, un tipo de renta a la baja también en el siglo XVII.

${ }^{13}$ AGS, CC., Memoriales, leg. 1104.

${ }_{14}$ Aunque a la hora de hacer estas afirmaciones conviene tener también en cuenta la política matrimonial de las familias, diferente en cada caso.

Is O. ReY CASTELAO, «Las economías monásticas femeninas ante la crisis del Antiguo Régimen», en I Congreso Internacional del monacato femenino en España, Portugal y América. 1492-1992, Universidad de León, 1993. Aporta datos de los ingresos de las Clarisas, Agustinas y Dominicas de Galicia. 
Hemos dejado a parte los ingresos diézmales porque no son un grupo homogéneo, no todos los conventos lo perciben y por otro lado supone una parte mínima de sus recursos económicos. Sería necesario un estudio individual de cada caso. Los conventos andaluces, por ejemplo, carecieron por completo de este ingreso ${ }^{16}$. No es una característica única de los conventos femeninos, los regulares masculinos tenían una participación también mínima, es el clero secular el que ostenta el mayor porcentaje. Dentro de esta desigualdad los conventos femeninos obtenían el $15,34 \%$, aproximadamente, del ingreso diezmal del clero regular ${ }^{17}$.

Las limosnas forman un apartado de los ingresos mucho más heterogéneo que no obedece a ningún parámetro exterior, pero de todos modos algunos conventos hicieron sus peticiones de socorro en base también a la escasez de limosnas. De la situación del convento de las descalzas franciscas de la ciudad de Valladolid (descalzas reales), se hizo eco el secretario de la Cámara Tomás de Angulo en un informe fechado en Madrid a 21 de diciembre de 1621 en el que expresaba que «por parte del monasterio real de las descalzas franciscas de la ciudad de Valladolid nos a sido echa relación que ellas no tienen situación ninguna, ni hasta aora les emos señalado alimentos para poderse sustentar y que las limosnas de esa ciudad son tan cortas que no llegan a tercia parte que antes solia aver, a cuya causa y por no tener como no tienen las cofradías, dotes y entierros y otras cosas de que sacaban más de 1.500 ducados cada año están empefiadas en más de 1.000 ducados sin tener con que repararse para el alimento de este año) ${ }^{18}$. Con el traslado de la Corte a Valladolid, los reyes Felipe III y, sobre todo, Margarita de Austria, se interesaron por este convento hasta el punto de asumir su patronato sustituyendo a don Francisco Enríquez de Almansa y su esposa doña Mariana de Zúñiga y Velasco que ostentaban el patronato desde 1595 , teniendo, incluso designada la capilla mayor para su enterramiento y habiendo adquirido en la escritura de patronato el compromiso de construir una casa, iglesia y nuevo monasterio; compromiso que después asumiría la Corona. A partir de entonces la vida del monasterio cambió por completo; se designó un número determinado de profesas que deberían ingresar sin dote, tal y como figura en la escritura de patronato suscrita por Felipe III en $1615^{19}$, se prohibían los enterramientos que no estuvieran permitidos por el monarca y éste se comprometía a entregar a la comunidad 500 ducados anuales. Además, tras la muerte de la reina, quedaban obligadas a dedicar la misa diaria al eterno descanso de su alma. Atendiendo al relato del monasterio parece ser que la dotación de 500

\footnotetext{
16 M. Garzón Pareja, Diezmos y tributos del clero de Granada, Granada, 1974.

17 O. REY CASTELAO, «Las economías monásticas femeninas...», p. 106.

18 AGS, CC., Memoriales, leg. 1117.

19 J. J. MarTinEZ, Catálogo monumental de la provincia de Valladolid, T. XIV, p. 92.
} 
ducados anuales no llegó a efectuarse pues en 1621, pasados seis años desde la formalización de la escritura de patronato, aseguran no tener ninguna asignación. El hecho de que las profesas ingresaran sin dote privaba a estas de sustento propio y la prohibición de enterramientos no autorizados dejaba al convento dependiente de las limosnas que ahora también se vuelven escasas.

\section{LAS PETICIONES DE MERCED (1598-1621)}

Así pues, ante la crisis del siglo XVII, reducidos sus medios de ingresos habituales, las peticiones de merced a la Cámara de Castilla se multiplican buscando el amparo de la gracia real. Al margen de las reformas, las órdenes femeninas continuaron bajo la protección de los monarcas, especialmente las de fundación real. Es a esta protección a la que se acogen cuando solicitan a la Cámara de Castilla alguna merced.

En 1619 la priora y monjas del monasterio de Santa Clara de Oviedo escriben a la Cámara solicitando una limosna. La Cámara encargó al corregidor de Oviedo hiciera averiguaciones sobre este convento el cuál contestó que no habría inconveniente en proveer alguna limosna ya que «el dicho monasterio es fundación real y que en el hay 80 religiosas profesas sin otras raciones menores, que es muy pobre y no tiene renta con que se poder sustentar y la poca que tiene gastan en reparos de ornamentos y servicio de culto divino y que aora tienen necesidad de levantar el coro que se les cayón ${ }^{20}$.

El propio significado de la palabra merced, remuneración por servicios prestados, implica además, la intención con la que se hace la súplica. El escaso «servicio» que para la sociedad ofrece el clero femenino, pues al vivir en clausura no realizan las mismas funciones de labor social que el clero masculino, hace que en sus peticiones sólo puedan aludir a la oración por el eterno descanso de los reyes como único servicio remunerable. Mediante el pago por servicios se acogen a la misma fórmula y a la misma vía de súplica que los oficiales al servicio del monarca. En ocasiones se desplazan y permanecen en la Corte enviando varias súplicas de tal forma que la Cámara concede limosnas «para que se vayan y no molesten más ${ }^{21}$.

Los memoriales son una vía rápida de solicitud pero también de libramiento. Normalmente la Cámara solía responder a las peticiones antes de quince días, si el asunto no entrañaba ninguna averiguación. Las diligencias solian hacerse por

29 AGS, CC., Memoriales, leg. 1103.

21 AGS, CC., Memoriales, leg. 988.

Actas del I Congreso de Historia de la Iglesia y el Mundo Hispánico Hispania Sacra, $52(2000)$ 
si se dañaba derechos de terceros o simplemente para comprobar la calidad del solicitante o si lo que pedía podía ser concedido y si no estaba concedido a otro. Según el caso, se consultaba en los libros de mercedes, que funcionaban como una especie de registro de antecedentes, para la concesión de determinados asuntos, es decir, si se había otorgado con anterioridad a ese mismo convento solía ser habitual concederlo otra vez.

Las peticiones solían ir adornadas con mucho dramatismo, no exento de realidad en la mayoría de los casos, pero que funcionaba muy bien a la hora de ser escuchadas. La priora del convento de Santa Isabel de Sevilla relataba en un memorial dirigido a la Cámara en 1598 la situación en estos términos: «Doña Bernardina de Valcaçar, en nombre de las demás monjas dize que por la mucha esterilidad de los años pasados y del presente padecen grandísima necesidad por que lo más del año no les dan ración dos días en la semana en su refitorio a cuya causa muchas de ellas morifían de hambre si sus padres y parientes y otros piadosos cristianos no las socorriesen» ${ }^{22}$.

Frente a las peticiones de otros colectivos o de individuos particulares las solicitudes de los conventos, tanto femeninos como masculinos, eran atendidas con bastante rapidez. A pesar de esto, algunos conventos decidían asegurarse el éxito y se dirigían a algún personaje influyente que intercediera por ellos. Por lo general este personaje solía ser el Duque de Lerma, que mediante una breve nota al Presidente de la Cámara de Castilla comunicaba la concesión de la merced o simplemente ponía en su boca las necesidades de las peticionarias. En 1611 escribía el Duque al Presidente de la Cámara: «La estrema necesidad que el convento de Sancta Ysavel de los Ángeles (monjas de la horden de San Francisco de la primera observancia de Sancta Clara) padesce, a obligado a esta ciudad a suplicar a su Majestad se sirva de mandar nombrar dos porteros reales, que están vacos en ella, dando facultad para que la abadesa y monjas presenten las personas que lo an de ser, permitiéndoles hagan alguna limosna, para remedio de la urgente necesidad que padescen y de la que tienen de rreparar el edificio de la casa que está a manifiesto a riesgo de arruynarse que sería de grandísimo sentimiento por ser antiquísimo y estar poblado de jente muy noble. Y assí suplica a Vuestra Excelencia Ilustrísima se sirva de faborescerlo y ampararlo con que se asegura del buen efecto como lo está de rezevir merced de Vuestra llustrísima ${ }^{23}$.

El contenido de las peticiones era muy variado. Unas pedían mercedes concretas, mientras otras se limitaban a solicitar una limosna. Cuando se trataba de simples solicitudes de limosna, el libramiento se hacía en dinero como meras

22 AGS, CC., Memoriales, leg. 802.
23 AGS, CC., Memoriales, leg. 987.

Actas del I Congreso de Historia de la Iglesia y el Mundo Hispánico Hispania Sacra, 52 (2000) 
ayudas de costa, o en el feble de alguna de las casas de moneda. Esta segunda fórmula era muy utilizada e incluso algunos conventos, sabedores de la facilidad con que se concedían este tipo de mercedes, las solicitaban directamente. Es el caso del convento de Santa María de Gracia de la ciudad de Sevilla, que en una petición dirigida en 28 de diciembre de 1598 , aluden que «por las muchas neccesidades de aquella casa, y particularmente la que aora de presente tiene por ciertas obras que en ella se hazen, suplican humilmente a Vuestra Majestad, que por limosna, les haga merced de mandar que se les de el feble de la casa de la moneda de la dicha ciudad de Sevilla o la parte del dicho feble que Vuestra Majestad fuere servido que en ello hará Vuestra Majestad servicio a Dios y a ellas muy gran merced». La Cámara contestó esa misma semana "dese a este monasterio 200 ducados en el feble por ayudar a estas obras ${ }^{24}$. Las Huelgas de la ciudad de Burgos en 1621 dirigían su petición «para que no dexe de ser esta obra tan amada de los esclarezidos reyes proxenitores de Vuestra Magestad se sirva de mandarla hazer merced del feble que resulta de los quinientos mil ducados que se labran en Burgos, que siempre acostumbra Vuestra Magestad mandarlos gastar en obras pías ${ }^{25}$. Esta forma de limosna fue la más común durante todo el reinado de Felipe III y se concedió a numerosos conventos: el de Nuestra Señora de la Misericordia de la ciudad de Toledo en $1598^{26}$, San José de Nuestra Seffora del Carmen de la villa de San Lucar la Mayor, las Carmelitas descalzas de la ciudad de Toledo, Santa Ana de Toro y San Pablo, también de Toledo, en $1600^{27}$, las descalzas Franciscas de la ciudad de Valladolid, en 1611 , en dos ocasiones ${ }^{28}$, etc. Sin embargo la peculiar situación de la moneda durante este reinado hizo que pronto surgieran protestas por parte de las diferentes casas de moneda en relación con estas limosnas, incluso el tesorero y oficiales de la casa de moneda de Valladolid, remitieron un memorial en el que explicaban al monarca la escasez de feble, no sólo en esta ciudad sino también en las casas de moneda de Granada, Cuenca, Toledo y Burgos, requiriendo al monarca a no conceder más limosnas, sobre todo en moneda de vellón ${ }^{29}$. La recomendación sin embargo no fue escuchada y continuaron librándose nuevas partidas que en muchos casos no podrán ser satisfechas hasta pasados varios años y tras la presentación de numerosos memoriales requiriendo el pago.

Distinto era el caso de aquellos conventos con mercedes perpetuas libradas anualmente. La difícil situación de la hacienda en los momentos finales del

\footnotetext{
${ }^{24}$ AGS, CC., Memoriales, leg. 798.

25 AGS, CC., Memoriales, leg. 1113.

${ }_{26}$ AGS, CC., Memoriales, leg. 799.

27 AGS, CC., Memoriales, leg. 802, 815 y 816.

${ }^{28}$ AGS, CC., Memoriales, leg. 981.

29 AGS, CC., Memoriales, leg. 1117.
} 
XVI y todo el XVII hacía que muchas de estas cargas adquiridas con anterioridad, en ocasiones desde la misma fundación, no pudieran retribuirse puntualmente y estuvieran pendientes de pago cantidades correspondientes a varios años seguidos. Las súplicas recordaban a la corona esta deuda año tras año hasta conseguir su pago. El convento de Santa María de Bretonera tenía concedida una merced anual de 265 fanegas de pan, por mitad de trigo y cebada, y 2.000 mrs. en dinero en concepto de ayuda a su sustento. En 1598 consiguieron cobrar la deuda correspondiente a 1595, 1596 y $1597^{30}$. El convento de San Miguel de los Ángeles, de la ciudad de Toledo, tenía concedida una limosna anual de $20.000 \mathrm{mrs}$., también como ayuda a su sustento, y al igual que las anteriores, en 1598 recibieron las cantidades adeudas de los años $1594,1595,1596$ y $1597^{31}$. Por lo general, este tipo de mercedes, se concedían a los conventos bajo patronato real, como el monasterio de la Vida Pobre de la ciudad de Toledo, cuya limosna anual consistía en 250 fanegas de pan $^{32}$. La paga de estas limosnas solía hacerse en aquello que estaba concedido, pero en ocasiones no se disponía de esa cantidad y la merced se trocaba por otra cosa más accesible, así el año de 1611 las 250 fanegas de este monasterio se entregaron en dinero procedido de los 18.000 ducados que Don Pedro Vélez de Avalos dejó por su testamento para limosnas. La libranza de estas partidas se hacía mediante el Consejo de Hacienda. La Cámara remitía una orden real al Consejo para que éste expidiera la provisión y cartas de libramiento ${ }^{33}$.

Las peticiones más comunes aludían al mal estado en que se encontraba el edificio o a sus escasas dimensiones, en algunos casos, debido a que algunos de estos conventos albergaban beaterios que hacían dificil la convivencia y la vida recogida de las profesas. En relación con esto escribían las religiosas de Santa Catalina de Siena, en Madrid, pidiendo una limosna para comprar otra casa «para apartar las religiosas -de las seglares- donde con quietud se den a Dios y se puedan governar ambas cosas mejon ${ }^{34}$. Estas súplicas para reparar o ampliar sus edificios solian socorrerse en dinero o en materiales para la construcción o en otros edificios en mejores condiciones, costeando la Cámara el traslado y en ocasiones la renta del inmueble.

${ }^{30}$ AGS, CC., Memoriales, leg. 796.

31 AGS, CC., Memoriales, leg. 796.

32 AGS, , CC., Memoriales, leg. 980.

${ }^{33}$ Con relación al monasterio de San Miguel de los Ángeles aparece una orden dirigida a la Contaduría Mayor de Hacienda para que se efectue la libranza en 18 de julio de 1598 de las cantidades adeudas de 1594, 1595, 1596 y 1597 advirtiéndose que «les librareys en qualesquier rentas destos nuestros reynos, las más cercanas de la dicha ciudad que ser pueda, con que no sea en el nuevo crecimiento». A.G.S., LC., 305, $\mathbf{f}^{\mathrm{P}} 232 \mathrm{v}$.

${ }^{34}$ AGS, CC., Memoriales, leg. 812.

Actas del I Congreso de Historia de la Iglesia y el Mundo Hispánico

Hispania Sacra, 52 (2000) 
En otros casos la única solución era el traspaso de la comunidad a otra órden, como el convento de Santa Ana en Toro, de la tercera regla de Santa Clara, que por no tener con que sustentarse pretendían, mediante una solicitud que llegó a la Cámara a través del duque de Lerma en 1600, reducirse a la órden de las Carmelitas descalzas. La misiva incluía una petición para que el rey escribiese al obispo de Zamora con el objeto de que éste, mientras se resolvía la solicitud, las socorriese con limosnas y mandase a otros conventos de la misma orden de la ciudad de Zamora a algunas de las religiosas «y particularmente a doña Leonor de Fuentes, que es monja antigua y que se sustentará sin pesadumbre por tener allí deudos que la acudirán a la necesidad $)^{35}$.

Otro tipo de peticiones trataban de sumarse a la tónica general de los tiempos y sus solicitudes pretendían negocios más lucrativos como los oficios públicos. La enajenación de estos oficios se convierte en una práctica común y recurso de la hacienda en estos momentos de crisis. Aunque el organismo encargado de ponerlos a la venta era el Consejo de Hacienda, la Cámara de Castilla se encargaba de recoger las peticiones y decidir su concesión. Unas veces lo que se concedía era el oficio en sí, por lo que si el comprador no estaba capacitado para servirlo, como es el caso de los conventos, debía nombrar un teniente que lo hiciera, y otras lo que se concedía era el dinero procedido de la venta de ese oficio. En 1598, se concedieron 600 ducados al monasterio de Santa Maria de Bretonera, procedidos de la venta de la escribanía del número de la ciudad de Oviedo $^{36}$. En 1612, se concede la propiedad de dos porterías reales al convento de Santa Isabel de los Ángeles, con facultad para nombrar a las personas que los han de servir ${ }^{37}$.

$\mathrm{Y}$ tal vez, el caso más representativo de concesión de todo tipo de mercedes, se resuma en la libranza de una hidalguía, en 1621, al convento real de las Huelgas de la ciudad de Burgos, con la única condición que se pusiera en manos de un cristiano viejo ${ }^{38}$.

Al comenzar esta comunicación sefialábamos que nuestra intención era la de añadir algunos apuntes sobre la forma de subsistir de los conventos femeninos. Los breves relatos que se nos ofrecen a través de los numerosos memoriales que se dirigieron a la Cámara de Castilla, en el periodo que aquí hemos presentado, creemos que nos han acercado un poco más a la situación que sufrieron durante un grave período de crisis que afectó a sus ingresos habituales. Insistimos en la necesidad de un estudio general que pueda aportar más luz a este apartado de la

\footnotetext{
35 AGS, CC., Memoriales, leg. 818.

36 AGS, CC., Memoriales, leg. 796.

37 AGS, CC., Memoriales, leg. 987.

38 AGS, CC, Memoriales, leg. 1117.
} 
Historia de la Iglesia, pero somos conscientes de lo que señalábamos en un principio: la disparidad de los casos y la escasez de datos, que en nuestro caso se ha reducido a los informes que los mismos conventos hacen al dirigir sus peticiones. 